Proceedings of the 48th International School and Conference on the Physics of Semiconductors "Jaszowiec 2019"

\title{
Influence of Active Layer Processing on Electrical Properties and Efficiency of Polymer-Fullerene Organic Solar Cells
}

\author{
W. Mech*, J. Borysiuk, A. Wincukiewicz, R. Bożek, P. Trautman, \\ M. TOKARCZyK, M. Kamińska And K.P. Korona \\ Institute of Experimental Physics, Faculty of Physics, University of Warsaw, \\ L. Pasteura 5, PL-02093 Warsaw, Poland
}

\begin{abstract}
New method of polymer-fullerene composite crystallization was examined as a possible way for efficiency enhancement of polymer organic solar cells. Since the structure of bulk-heterojunction is crucial for its efficiency, there is a strong need for new methods that can control a crystallization process. In this work we studied the crystallization process taking place under thermal annealing in ambient conditions, as well as annealing in a solvent atmosphere. Two polymer compounds, P3HT and PTB7, performing as donor materials were used. The acceptor material in the fabricated bulk heterojunction was [6,6]-phenyl-C61-butyric acid methyl ester (PCBM). The spin-coated layers were investigated by optical absorption and X-ray diffraction. We observed significant changes in the crystal structure of some of the annealed layers. The constructed solar cells were examined with use of current-voltage characterization method under AM1.5G sun irradiation, and by photocurrent spectroscopy. In the case of P3HT:PCBM cells significant increase of efficiency was observed, especially after annealing in solvent atmosphere.
\end{abstract}

DOI: $10.12693 /$ APhysPolA.136.579

PACS/topics: $72.40 .+\mathrm{w}, 72.80 . \mathrm{Le}, 78.70 . \mathrm{Ck}$

\section{Introduction}

Organic photovoltaic cells with a polymer:fullerene bulk heterojunction active layer are inexpensive sources of renewable energy, having maximum reported efficiency of about $11 \%$ [1]. The most popular acceptor materials are fullerene derivatives, while there is a broad range of proposed donor materials ranging from the most popular polythiophenes [2-8] to less popular but promising polyazomethines $[9,10]$. The main research on improvement of polymer: fullerene cell efficiency is focused on two approaches: (i) searching for better polymer that would have a smaller energy gap, more suitable highly occupied molecular orbital (HOMO) and lowly unoccupied molecular orbital (LUMO) energy levels regarding the acceptor respective ones, and increased carrier mobilities; (ii) improvement of crystal structure in order to obtain better electrical parameters (higher conductivity, lower leakage). Lower energy gap results in absorption in the wider range of solar radiation since the energy of the absorbed photon must be higher or equal to energy gap of donor material (P3HT - $1.9 \mathrm{eV}$, PTB7 - $1.6 \mathrm{eV})$. The HOMO and LUMO energy levels of donor and acceptor materials should be carefully chosen since the well matched mutual energy levels improve exciton separation. Good structure of active layer is equally of high importance. The most of light absorption is ex-

*corresponding author; e-mail: wojciech.mech@fuw.edu.pl pected to occur inside donor molecules. The incoming photon creates an exciton there, that latter diffuses to the donor:acceptor interface, where it dissociates in a chargetransfer process, i.e., the hole stays at the donor material while the electron is transferred to the acceptor material. Finally, the separated charges are transported by molecular networks to electrodes. Improvement of crystal structure should lead to better carrier mobility, which is generally low, like in hopping transport. On the other hand, because of low mobility, it is crucial to obtain layer structure with the shortest possible carrier paths and crystallization should help in this aspect, too. In our research we examined the influence of thermal [11-13] and solvent annealing $[2,3,12,14-21]$ techniques on improving optical, crystal, and electrical parameters of P3HT:PTB7 organic cells.

The main goal of the solvent annealing techniques is elongation of crystallization time of organic compounds by annealing in solvent vapor environment. The lower rate of crystallization is due to decrease of solvent evaporation from the deposited layer. The conducting conjugated polymers has high tendency to self-organize, but in standard spin-coating procedures crystallization time is not long enough (only a few seconds) for material ordering. Thanks to the solvent annealing technique this time can be extended to several minutes.

\section{Samples preparation and experiment details}

The solar cells based on conducting conjugated polymers use bulk heterojunction (BHJ) configuration for electron and hole generation and their separation. 
The BHJ solar cells comprised of nanoscale interpenetrating networks of donor and acceptor materials are shown in Fig. 1. The acceptor material was PCBM (Fig. 1b). Two alternative polymer compounds: poly(3-hexylthiophene-2,5-diyl) (P3HT) or poly(4,8bis [(2-ethylhexyl)oxy]benzo[1,2-b:4,5-b']dithiophene-2,6diyl-alt-3-fluoro-2-[(2-ethylhexyl)carbonyl] thieno[3,4-b] thiophene-4,6-diyl) (PTB7) were used as donor materials (Fig. 1c and d). The solar cells were fabricated on substrates covered with conductive and transparent indium-tin oxide (ITO). The substrates had 8 separated pixels with area of $4 \mathrm{~mm}^{2}$ each. The efficient flow of holes and suppression of electron leakage to the ITO anode is secured by PEDOT:PSS electron blocking layer.

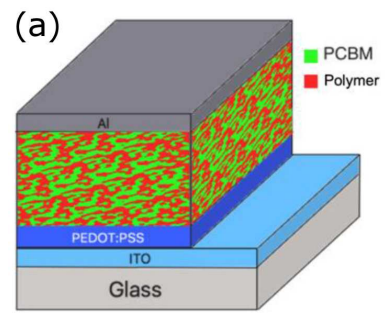

(c)

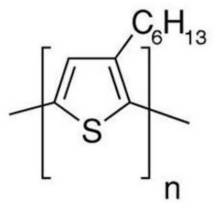

(b)

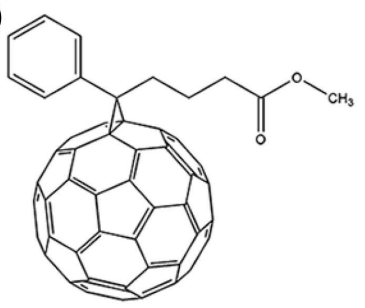

(d)

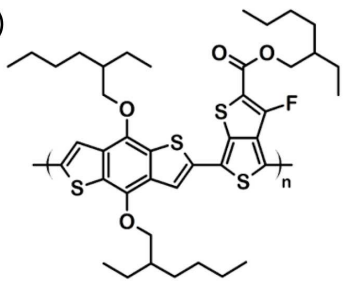

Fig. 1. Scheme of the fabricated polymer-fullerene solar cells (a). Conducting organic compounds used in the polymer solar cells: acceptor material $\mathrm{PC}_{60} \mathrm{BM}(\mathrm{b})$, and donors P3HT (c) and PTB7 (d).

P3HT and $\mathrm{PC}_{60} \mathrm{BM}$ were purchased from SigmaAldrich, whereas PTB7, PEDOT:PSS and ITO 8 pixel glass substrates - from Ossila.

The ITO-covered and pure glass substrates were cleaned before layer deposition in ultrasonic cleaner $\left(70^{\circ} \mathrm{C}\right)$ and dried by compressed nitrogen. Then the surface was activated by UV ozone cleaner. The solutions of organic compounds were prepared in chlorobenzene in the following concentrations: (1) P3HT $15 \mathrm{mg} / \mathrm{ml}$, (2) P3HT:PCBM $25 \mathrm{mg} / \mathrm{ml}$ in 3:2 ratio, (3) PTB7 $25 \mathrm{mg} / \mathrm{ml}$, (4) PTB7 $10 \mathrm{mg} / \mathrm{ml}$, and (5) PTB7:PCBM $25 \mathrm{mg} / \mathrm{ml}$ in $2: 3$ ratio. The solutions were heated at $40^{\circ} \mathrm{C}$ and stirred for $24 \mathrm{~h}$. Before deposition they were cooled down and filtered through $0.45 \mu \mathrm{m}$ PTFE syringe filter.

Solar cell preparation began with spin-coating of PEDOT:PSS layer on a few ITO glass substrates in air, with speed of $5000 \mathrm{rpm}$, and the obtained layers were annealed at $150{ }^{\circ} \mathrm{C}$ for $15 \mathrm{~min}$. Then such coated substrates were moved to argon glove box where active layers were deposited also by spin coating. The rotation speed was this time $1500 \mathrm{rpm}$ or $900 \mathrm{rpm}$ for P3HT:PCBM and
PTB7:PCBM mixtures, respectively. The active layer was either dried at room temperature under ambient conditions (further referred to as non-annealed, NA), or thermally annealed at $150{ }^{\circ} \mathrm{C}$ for $15 \mathrm{~min}$ (TA), or solvent annealed in room temperature for $5 \mathrm{~min}$ in chlorobenzene vapors (SA). Finally, Al cathode was thermally evaporated through a mask on the structure, and the obtained cell was encapsulated with glass and UV-cured epoxy. For optical absorption spectroscopy, microscopy, and X-ray research the organic layers were deposited on pure glass substrates by identical procedure as the solar cells. Thickness of the obtained layers was checked with a profilometer and was as follows: $40 \mathrm{~nm}$ for PEDOT:PSS, $150 \mathrm{~nm}$ for P3HT:PCBM, $90 \mathrm{~nm}$ for PTB7:PCBM, and $100 \mathrm{~nm}$ for Al cathode.

Current-voltage characteristics were measured by Keithley 2450 Source Meter with Kickstart PC software, and using Ossila 8 pixel test board. As a source of illumination Newport VeraSol-2 LED Class AAA Solar Simulator of $1000 \mathrm{~W} / \mathrm{m}^{2}$ power output and AM1.5G spectrum was applied. Average PCE was calculated for 8 pixels of each cell.

Photocurrent spectroscopy (PCS) measurements were performed in the spectral range of 320 to $1400 \mathrm{~nm}$ (0.8 to $3.9 \mathrm{eV})$, using tungsten lamp with a monochromator. The current was measured in a short circuit mode $\left(I_{\mathrm{SC}}\right)$ by Keithley picoammeter, so the $I_{\mathrm{SC}}$ spectra (short-circuit photocurrent vs. wavelength) were registered.

Optical absorption spectra were obtained by means of Carry 5000 UV-Vis-NIR spectrophotometer in the spectral range of 200 to $1200 \mathrm{~nm}$, and were converted into absorption coefficient spectral dependence.

The crystal structure of organic layers was studied using grazing incidence X-ray diffraction (GIXRD) in the in-plane configuration. GIXRD spectra were measured using X'Pert Philips diffractometer with $\mathrm{Cu} K_{\alpha}$ $(\lambda=1.542 \AA)$ line as a source of radiation in $2 \Theta$ angle range $3.8^{\circ}-28^{\circ}$. The angle of incident was $0.18^{\circ}$. Average crystallite size, $d$, was calculated from the widths of the diffraction peaks, $W$, by the Scherrer equation

$$
d=\frac{K \lambda}{W \cos (\theta)},
$$

where $\lambda$ is X-ray wavelength, $K$ is Scherrer constant with assumed $K=0.94$, and $\theta$ is the Bragg angle.

Atomic force microscopy (AFM) images were obtained in topography and phase modes. Size of the observed area was $1 \times 1 \mu \mathrm{m}^{2}$.

\section{Results and discussion}

One of the most important function of polymer in solar cell is absorption of light. The materials selected for solar cells must have high absorption coefficients, of the order of $10^{5} / \mathrm{cm}$. It is also important that they should be spectrally matched to solar radiation. These properties were analyzed with use of optical absorption (OA). 

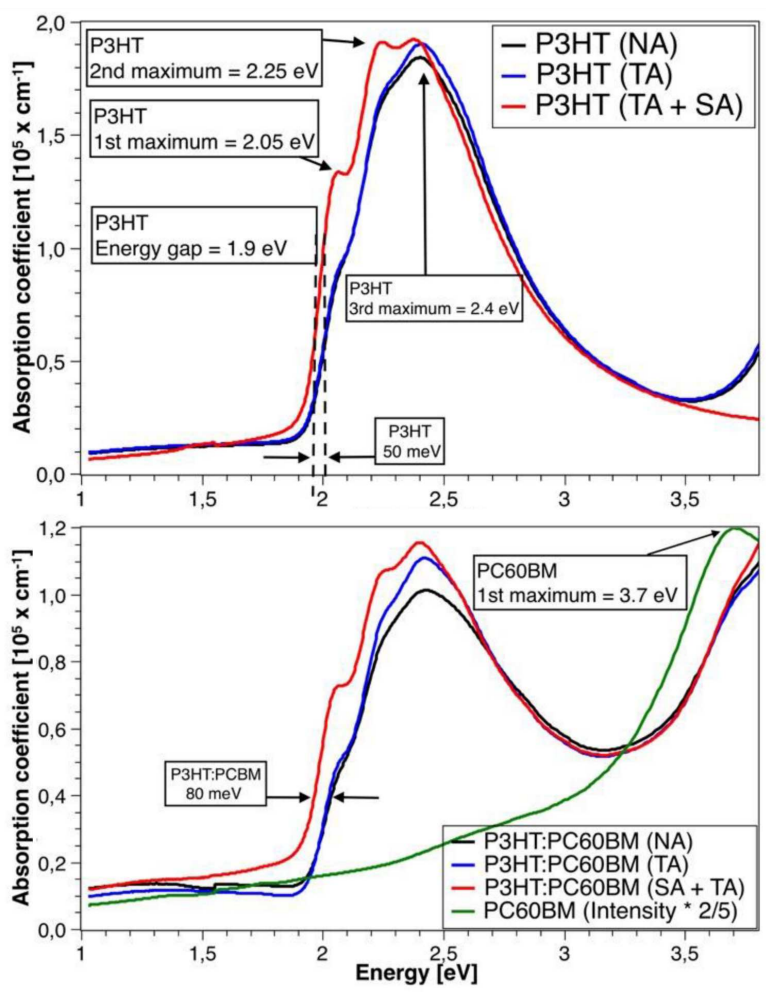

Fig. 2. Optical absorption spectra of P3HT (upper curves) and P3HT:PCBM (lower curves) thin layers after different annealing procedures.
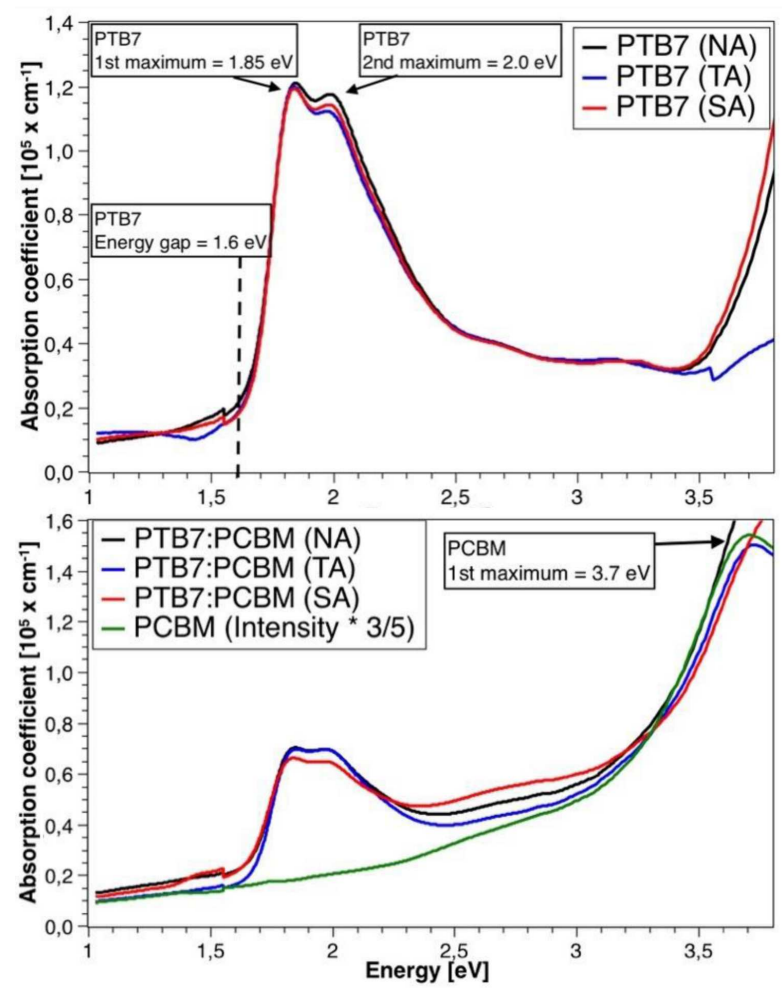

Fig. 3. Optical absorption spectra of PTB7 (upper curves) and PTB7:PCBM (lower curves) thin layers after different annealing procedures.
The OA spectra of P3HT (Fig. 2) show high absorption coefficient, and the signal starts at $1.9 \mathrm{eV}$ which exactly suites to P3HT HOMO-LUMO gap [22]. The maximum is at $2.4 \mathrm{eV}$, and the absorption decreases above $2.7 \mathrm{eV}$. This spectral range is quite well-matched to the solar radiation spectrum. The next band starts in UV at $3.3 \mathrm{eV}$. The spectra of P3HT and P3HT:PCBM layers showed large influence of annealing procedures. The lowest absorption was obtained for the not annealed layer (NA), which showed one smooth band. After thermal annealing (TA) the absorption increased and it was possible to resolve three peaks at $2.05 \mathrm{eV}, 2.25 \mathrm{eV}$, and $2.4 \mathrm{eV}$ forming the absorption band. Solvent annealing induced further improvement of the spectrum. Application of solvent annealing caused narrowing of the peaks and red-shift of the low energy absorption edge by $50 \mathrm{meV}$ for pure P3HT layer, and by $80 \mathrm{meV}$ for P3HT:PCBM bulk heterojunction. Such improvement of OA spectra, especially sharpening of the peaks can be associated with improved crystal structure.

Absorption spectrum of PTB7 polymer starts at $1.6 \mathrm{eV}$ which is due to smaller energy gap of PTB7 comparing to P3HT (Fig. 3). An absorption band is centered at $1.9 \mathrm{eV}$ with two peaks at $1.85 \mathrm{eV}$ and $2.00 \mathrm{eV}$. PTB7 absorption coefficient is almost twice smaller than for P3HT. Also, the absorption spectral range of $1.6 \mathrm{eV}-2.5 \mathrm{eV}$ is significantly narrower than for P3HT. However, it fits much better to the solar radiation spectrum that has maximum at $1.4 \mathrm{eV}$, so PTB7 can harvest more photons and generate more electrical current, and finally PTB7based solar cells are of higher efficiency than the ones based on P3HT. The annealing treatments of PTB7 and PTB7:PCBM layers do not show significant changes in the spectra. Only small changes (low decrease) in the absorption intensity after $\mathrm{SA}$ are visible, but there is no significant change in the spectrum shape.

The PCBM absorption spectrum has no peaks. It starts at about $1.5 \mathrm{eV}$ and the absorption coefficient is very low, but it slowly increases with energy reaching significant values at UV range, for energies above $3 \mathrm{eV}$.

Generally, for solar cell the absorbed photon should produce one electron (the Stoletov law), however, there is always a lot of parasitic processes that result in external quantum efficiency (EQE) lower than 1. In order to determine $\eta_{\mathrm{EQE}}$ we measured photocurrent spectrum and divided the obtained short-circuit photocurrent $I_{\mathrm{SC}}(\lambda)$ by the photon flux $\Phi(\lambda)$,

$$
\eta_{\mathrm{EQE}}(\lambda)=I_{\mathrm{SC}}(\lambda) / \Phi(\lambda),
$$

The EQE spectra plotted in Fig. 4 show quite good correlation with the absorption spectra of the polymer:PCBM layers. For example, it can be noticed that for P3HT-based cell the strong current generation begins at $1.9 \mathrm{eV}$, and its EQE has maximum at $2.4 \mathrm{eV}$ (third peak of the OA spectrum). The second maximum, visible at $3.2 \mathrm{eV}$, can be associated with the higher excited states of P3HT. One can notice also a weaker peak at $3.5 \mathrm{eV}$ associated with PCBM. The low-intensity signal that starts 
at about $1.5 \mathrm{eV}$ is either due to absorption in PCBM or in polymer-PCBM complex [9]. The important observation comes from the SA P3HT cell. It occurs that the solvent annealing redshifted the spectral range of EQE by the same energy $80 \mathrm{meV}$ as in the case of OA spectra of P3HT:PCBM. Since the flux of solar photons in this range is high, such shift leads to substantial improvement of photogeneration efficiency. Also photocurrent generated at the $2.4 \mathrm{eV}$ peak was higher after SA procedure. The PTB7-based cell shows EQE edge at smaller energy, $1.6 \mathrm{eV}$, similarly to OA spectrum of PTB7. For both EQE and absorption spectra the annealing caused only a small decrease of PTB7 peak intensity, but did not change the line shape.

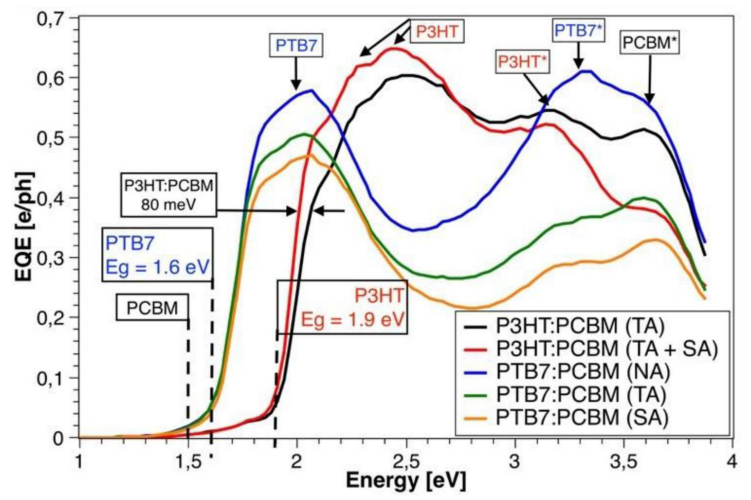

Fig. 4. EQE spectra of P3HT:PCBM and PTB7:PCBM cells after different annealing procedures.

The power obtained from a solar cell is a product of current $I_{m p}$ and voltage $V_{m p}$ at maximum power, so the power conversion efficiency (PCE) was determined from current-voltage characteristics measured under AM1.5G irradiation.

The current density versus voltage curves are plotted in Fig. 5 in negative convention, so the reverse current has a positive value. It can be observed that the $I-V$ characteristics for P3HT:PCBM cells showed significant increase of efficiency after the annealing procedures. Electrical parameters calculated from the I-V curves are shown in Table I. Sample with no annealing treatment was characterized by low efficiency, $0.37 \%$. After thermal annealing the efficiency rose to $2.06 \%$, especially due to increase of short circuit current density, $J_{S C}$. We can estimate that this effect was due to twice lower leakage current and about 5 times smaller serial resistance. After solvent annealing we observed further increase of electrical parameters resulting in $2.54 \%$ efficiency. In this case, the increases of current density and fill factor were related to wider optical absorption range and decrease of serial resistance of the cell, most probably due to higher carrier mobility, more favorable polymer-fullerene phase separation, and bigger crystallite size. Most probably the improvement of these factors after annealing processes is associated with reinforced ordering of P3HT:PCBM crystal structure.
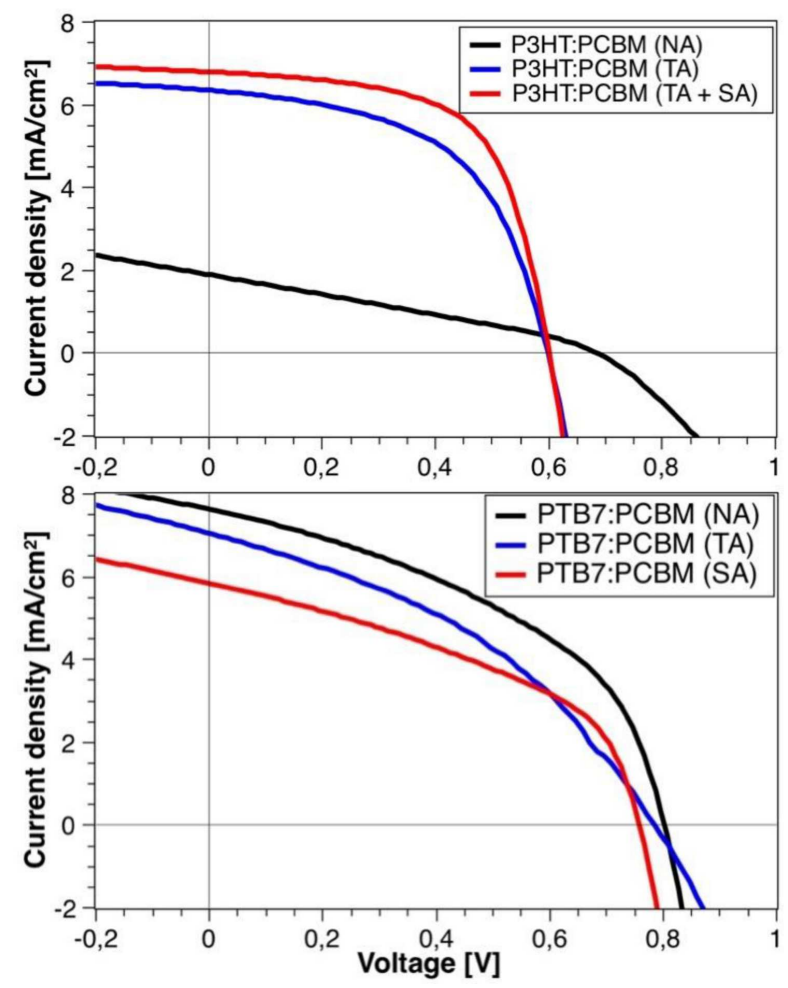

Fig. 5. $\quad I-V$ characteristics of P3HT:PCBM (upper figure) and PTB7:PCBM (lower figure) cells after different annealing procedures.

TABLE I

Electrical parameters of organic solar cells after different annealing procedures.

\begin{tabular}{l|c|c|c|c|c}
\hline \hline \multicolumn{1}{c|}{ Sample } & $\begin{array}{c}U_{\mathrm{OC}} \\
{[\mathrm{V}]}\end{array}$ & $\begin{array}{c}J_{\mathrm{SC}} \\
{\left[\mathrm{mA} / \mathrm{cm}^{2}\right]}\end{array}$ & $\begin{array}{c}\text { FF } \\
{[\%]}\end{array}$ & $\begin{array}{c}\text { Best PCE } \\
{[\%]}\end{array}$ & $\begin{array}{c}\text { Average } \\
\text { PCE [\%] }\end{array}$ \\
\hline P3HT:PCBM \\
& 0.69 & 1.89 & 29 & 0.37 & 0.34 \\
P3HT:PCBM $^{b}$ & 0.59 & 6.35 & 55 & 2.06 & 1.95 \\
P3HT:PCBM $^{b, c}$ & 0.59 & 6.79 & 63 & 2.54 & 2.41 \\
PTB7:PCBM $^{a}$ & 0.81 & 7.62 & 44 & 2.71 & 2.41 \\
PTB7:PCBM $^{b}$ & 0.78 & 7.04 & 39 & 2.15 & 1.93 \\
PTB7:PCBM $^{c}$ & 0.76 & 5.85 & 43 & 1.92 & 1.72 \\
\hline$a$
\end{tabular}

The data for PTB7:PCBM cells showed about $0.2 \mathrm{~V}$ higher open circuit voltage $U_{\mathrm{OC}}$ and about $1 \mathrm{~mA} / \mathrm{cm}^{2}$ higher current density, relative to P3HT:PCBM. This is connected with $0.15 \mathrm{eV}$ lower PTB7 HOMO energy level, and smaller energy gap of PTB7, relatively. The highest efficiency of $2.71 \%$ was observed for PTB7:PCBM cell without any annealing. Thermal or solvent annealing decreased the efficiency of the cell due to reduction of current density and fill factor. It can be concluded that for fabrication of PTB7-based solar cells ambient conditions are better than solvent vapor atmosphere.

GIXRD spectra of P3HT and P3HT:PCBM samples showed (100) diffraction peak for $2 \Theta=5.4^{\circ}$ angle, which corresponds to oriented P3HT layers (see Fig. 6). 

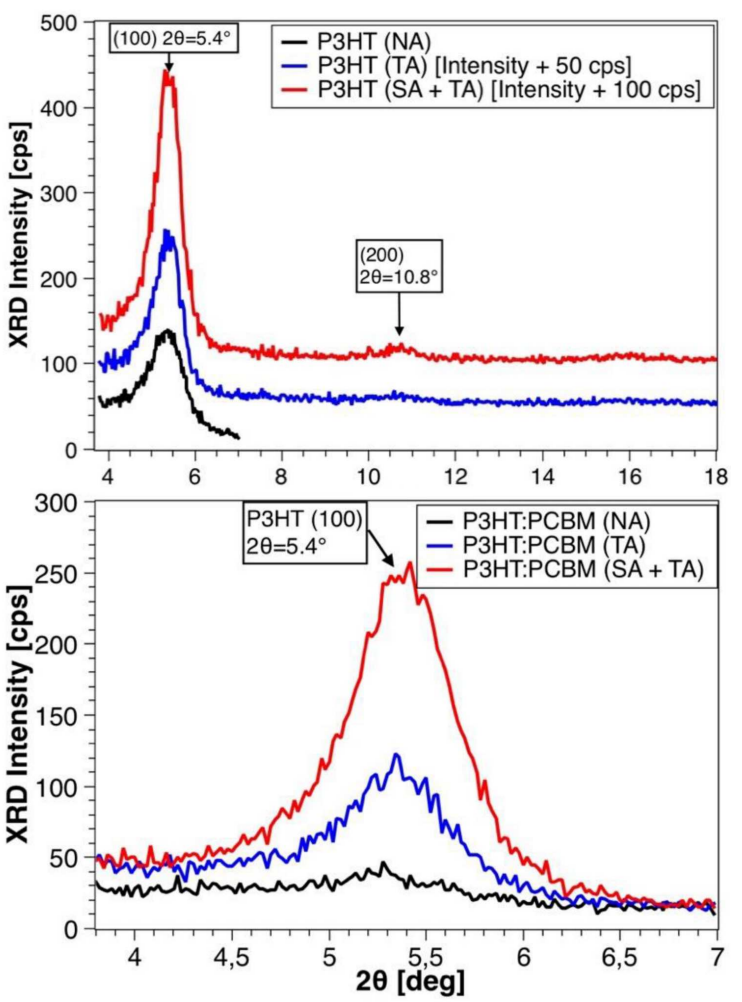

Fig. 6. Grazing incidence XRD spectra of P3HT (upper curves) and P3HT:PCBM (lower curves) layers after different annealing procedures.

TABLE II

X-ray parameters after different annealing procedures.

\begin{tabular}{l|c|c|c}
\hline \hline $\begin{array}{c}\text { Sample } \\
\text { (preparation) }\end{array}$ & $\begin{array}{c}\text { (100) Intensity } \\
{[\mathrm{cps}]}\end{array}$ & $\begin{array}{c}(100) \text { FWHM } \\
{\left[{ }^{\circ}\right]}\end{array}$ & $\begin{array}{c}\text { Av. crystallite } \\
\text { size }[\mathrm{nm}]\end{array}$ \\
\hline P3HT $^{a}$ & 110 & 0.94 & 8.84 \\
P3HT $^{b}$ & 196 & 0.88 & 9.45 \\
P3HT $^{c}$ & 306 & 0.73 & 11.39 \\
P3HT:PCBM $^{a}$ & 64 & 0.62 & 13.41 \\
P3HT:PCBM $^{b}$ & 106 & 0.58 & 14.33 \\
P3HT:PCBM $^{c}$ & 232 & 0.55 & 15.11 \\
\hline
\end{tabular}

${ }^{a}$ no thermal annealing, ${ }^{b}$ thermal annealing, ${ }^{c}$ solvent annealing

These spectra suggest "edge on" orientation of P3HT molecules in agreement with reports of such behavior when chlorobenzene is used as a solvent [23]. Such configuration is the most desired for solar cell application. The calculated $d$-spacing for $5.4^{\circ}$ peak was $1.63 \mathrm{~nm}$. For pure P3HT we obtained second order diffraction peak (200). The results of (100) peak analysis with use of Eq. (1) (see Table II) showed better crystal structure of P3HT and P3HT:PCBM after thermal annealing and its further improvement after solvent annealing procedure (higher intensity peak). The annealing led also to the peak narrowing, which is connected with increase of the average crystallite size. Larger crystallite size could lead to better electrical paths for excited holes moving from P3HT to ITO anode.
The topography AFM images (not shown) gave root mean square equal to $1.27 \mathrm{~nm}$ for P3HT:PCBM, and $1.04 \mathrm{~nm}$ for PTB7:PCBM. These numbers indicate low roughness of the spin-coated layers, which is a desirable feature. The AFM phase image for the thermally annealed P3HT:PCBM showed polymer-fullerene phase separation with diameter of P3HT crystallites of about $20 \mathrm{~nm}$ (Fig. 7). This number is similar to the crystallite size calculated form GIXRD spectra. The AFM phase images for PTB7:PCBM showed picture of more heterogeneous phase separation (Fig. 7). Bigger domains with size of about $50 \mathrm{~nm}$ were decorated with single polymer fibers of width equal to about $5 \mathrm{~nm}$. Such single polymer fibers of PTB7 can improve charge separation by increase of donor/acceptor interfaces.
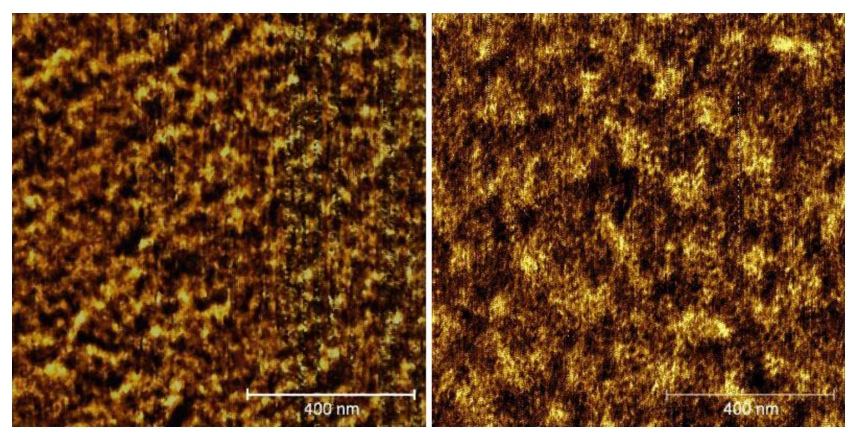

Fig. 7. AFM phase images $\left(1 \times 1 \mu \mathrm{m}^{2}\right)$ of thermally annealed P3HT:PCBM (left) and as deposited PTB7:PCBM (right) organic thin layers.

\section{Conclusions}

We showed improvement of absorption, electrical parameters, efficiency, and crystal structure of $\mathrm{P} 3 \mathrm{HT}$ and P3HT:PCBM after thermal or solvent annealing. The key technique is thermal annealing, but solvent annealing leads to further improvement of P3HT:PCBM cell performance. The solvent annealing improves spectral absorption and EQE by shifting absorption threshold by $80 \mathrm{meV}$ to the red which significantly increases the number of absorbed photons. It also enhances electrical parameters which we attribute to better crystal structure of the SA layers judging from sharper OA and XRD peaks. The solvent annealed P3HT layer gives the most intense GIXRD diffraction peaks and the biggest average crystallite size $(\approx 15 \mathrm{~nm})$. Finally, all these improvements resulted in increase of power conversion efficiency up to $2.5 \%$.

For PTB7 polymer we found that ambient conditions are the best for crystallization in comparison with thermal and solvent procedures. Annealing techniques did not influence the PTB7 absorption and EQE spectra, and unfortunately they even worsened electrical parameters of the photovoltaic cells. However, due to good spectral range of $\mathrm{PTB} 7$, the highest obtained PCE value was $2.7 \%$. 


\section{Acknowledgments}

The research described in this paper was financed by the National Centre for Research and Development (Poland) under the project TECHMATSTRATEG1/347431/14/NCBR/2018.

\section{References}

[1] W. Li, J. Cai, F. Cai, Y. Yan, H. Yi, R.S. Gurney, D. Liu, A. Iraqi, T. Wang, Nano Energy 44, 155 (2018).

[2] C. Deibel, V. Dyakonov, Rep. Prog. Phys. 73, 096401 (2010)

[3] M.T. Dang, L. Hirsch, G. Wantz, Adv. Mater. 23, 3597 (2011).

[4] Organic Solar Cells: Fundamentals, Devices, and Upscaling, Eds. H. Richter, B.P. Rand, Jenny Stanford Publ., [317 - 366] 2014.

[5] J. Jo, S. Na, S. Kim, T. Lee, Y. Chung, S. Kang, D. Vak, D. Kim, Adv. Function. Mater. 19, 2398 (2009).

[6] H.C. Liao, C.S. Tsao, Y.C. Huang, M.H. Jao, K.Y. Tien, C.M. Chuang, C.Y. Chen, C.J. Su, U.S. Jeng, Y.F. Chen, W.F. Su, RSC Adv. 4, 6246 (2014).

[7] J.Y. Na, B. Kang, D.H. Sin, K. Cho, Y.D. Park, Sci. Rep. 5, 13288 (2015).

[8] Q.L. Jiang, C.C. Liu, H.J. Song, H. Shi, Y.Y. Yao, J.K. Xu, G. Zhang, B.Y. Lu, J. Mater. Sci. Mater. Electron. 24, 4240 (2013).

[9] A. Iwan, B. Boharewicz, I. Tazbir, M. Malinowski, M. Filapek, T. Kłab, B. Luszczynska, I. Glowacki, K.P. Korona, M. Kaminska, J. Wojtkiewicz, M. Lewandowska, A. Hreniak, Solar Energy 117, 246 (2015)
[10] K.P. Korona, T. Korona, D. Rutkowska-Zbik, S. Grankowska, A. Iwan, M. Kamińska, J. Phys. Chem. Solids 86, 186 (2015).

[11] L. Chang, H.W. Lademann, J. Bonekamp, K. Meerholz, A.J. Moulé, Adv. Function. Mater. 211779 (2011).

[12] M. Campoy-Quiles, T. Ferenczi, T. Agostinelli, P.G. Etchegoin, Y. Kim, T.D. Anthopoulos, P.N. Stavrinou, D.D.C. Bradley, J. Nelson, Nat. Mater. 7, 158 (2008).

[13] G. Li, V. Shrotriya, J. Huang, Y. Yao, T. Moriarty, K. Emery, Y. Yang, Nat. Mater. 4864 (2005).

[14] H. Chang, P. Wang, H. Li, J. Zhang, D. Yan, Synth. Met. 184, 1 (2013)

[15] A. Bagui, S.S.K. Iyer, IEEE Trans. Electron. Dev. 58, 4061 (2011).

[16] B. Jung, K. Kim, W. Kim, J. Mater. Chem. A 2, 15175 (2014).

[17] F.C. Chen, C.J. Ko, J.L. Wu, W.C. Chen, Sol. Energy Mater. Sol. Cells 94, 2426 (2010)

[18] E. Verploegen, C.E. Miller, K. Schmidt, Z. Bao, M.F. Toney, Chem. Mater. 24, 3923 (2012).

[19] J.H. Park, J.S. Kim, J.H. Lee, W.H. Lee, K. Cho, J. Phys. Chem. C 113, 17579 (2009).

[20] G. Li, Y. Yao, H. Yang, V. Shrotriya, G. Yang, Y. Yang, Adv. Funct. Mater. 17, 1636 (2007).

[21] W. Wang, S. Guo, E.M. Herzig, K. Sarkar, M. Schindler, D. Magerl, M. Philipp, J. Perlich, P. Müller-Buschbaum, J. Mater. Chem. A 4, 3743 (2016).

[22] P. Kumar, Organic Solar Cells: Device Physics, Processing, Degradation, and Prevention, 1st ed., CRC Press, 2016.

[23] M. Brinkmann, J. Polym. Sci. Part B Polym. Phys. 49, 1218 (2011) 